\title{
Recent Trends in Bacteriology of Adult Patients with Chronic Rhinosinusitis
}

\author{
Doyeon Kim ${ }^{1, \dagger}{ }^{,}$Abdullah M. Assiri ${ }^{1,2,+}$ and Ji Heui Kim ${ }^{1, *(1)}$ \\ 1 Department of Otorhinolaryngology-Head and Neck Surgery, Asan Medical Center, University of Ulsan \\ College of Medicine, Seoul 05505, Korea; kdyrkfmfmfm@gmail.com \\ 2 Department of Otolaryngology-Head and Neck Surgery, College of Medicine, Najran University, King \\ Abdulaziz Road, Najran 1988, Saudi Arabia; aamodrba@nu.edu.sa \\ * Correspondence: jhkim0217@amc.seoul.kr; Tel.: +82-3010-3710 \\ + These authors contributed equally to this work.
}

Received: 22 September 2019; Accepted: 4 November 2019; Published: 6 November 2019

\begin{abstract}
This study aimed to identify trends in bacteria isolated from Korean adults with chronic rhinosinusitis (CRS). Enrolled were CRS patients who underwent sinus bacterial culture during endoscopic sinus surgery between 2007-2008, 2011-2012, and 2017-2018 $(n=510)$. Patients' clinical characteristics, bacterial culture results, and antibiotic resistance were reviewed. The bacteria isolation rate was $76.3 \%$ (73.9\% for CRS with nasal polyps and $82.8 \%$ for CRS without nasal polyps; $p=0.038$ ). In total, 650 strains were isolated, the most common was Coagulase Negative Staphylococci (CNS) $(28.0 \%)$, followed by Streptococcus species (12.2\%), Propionibacterium species $(8.0 \%)$, Corynebacterium species (7.5\%), Staphylococcus aureus (6.2\%), Haemophilus species (5.7\%), Klebsiella species (5.1\%), and Pseudomonas aeruginosa (4.2\%). Furthermore, an analysis of the bacterial trends in the three groups showed significant increases over time for the isolation of CNS $(p=0.006)$, Klebsiella $(p=0.002)$, and P. aeruginosa $(p=0.007)$ and extended-spectrum beta-lactamase (ESBL) producing Klebsiella $(p<0.001)$ and Enterobacter ( $p=0.007$ ) species in terms of antibiotics resistance. This study demonstrates that the frequency of CNS, Klebsiella, and P. aeruginosa in CRS patients and the ESBL-producing Klebsiella and Enterobacter species has significantly increased in CRS patients over the last decade.
\end{abstract}

Keywords: microbiology; chronic rhinosinusitis; bacteria; swab; culture; endoscopic sinus surgery

\section{Introduction}

Chronic rhinosinusitis (CRS) is an inflammatory mucosal disease of the nasal cavity and paranasal sinuses that lasts more than 12 weeks. CRS is phenotypically classified as either CRS with nasal polyps (CRSwNP) or CRS without nasal polyps (CRSsNP). The current hypothesis of CRS pathogenesis involves dysfunctional host-environmental interactions involving various exogenous pathogens and changes in the sinonasal mucosa. Although the role of bacteria as exogenous pathogens in the initial establishment of CRS remains unclear, an impaired local immune system in the sinonasal mucosa does allow colonization and overgrowth of bacteria that subsequently induce an inflammatory and immune response. Moreover, bacteria can trigger an acute exacerbation of CRS, contributing to ongoing, recalcitrant CRS [1,2].

CRS affects the quality of life. Purulent nasal discharge (anterior or posterior or both) is not only a diagnostic criterion of CRS but also one of the most common symptoms that make CRS patients uncomfortable. Although microbiome studies have reported various organisms and their important roles in the pathophysiology of CRS [3], the selection of antibiotics for infectious exacerbations in CRS patients is recommended to follow the results of bacterial culture, ideally endoscopically guided culture [1,4]. Antibiotics for CRS in South Korea have been abused (e.g., by being prescribed in 
the absence of culture data), fueling concerns about the emergence of atypical bacterial strains and antibiotic-resistant strains. Such problems can contribute to an increased incidence of refractory CRS after endoscopic sinus surgery (ESS). Therefore, sinus bacterial cultures during ESS are necessary to guide targeted antibiotic treatment after ESS [2,5]. Furthermore, a study of the recent bacteriological trends in CRS patients may contribute to the management of bacteriology after ESS.

We have routinely performed endoscopically guided bacterial culture from the sinus during ESS. Endoscopically guided culture is an acceptable method for obtaining bacteria cultures from patients with CRS [2,5-7]. The aim of this study was to investigate the bacterial strains that are frequently isolated from patients who underwent endoscopically guided bacterial culture from sinus during ESS performed within two-year periods spaced at five-year intervals over the last ten years (2007-2008, 2012-2013, and 2017-2018), changes in trends of bacteria, and their antibiotic resistance in Korean adult patients with CRS.

\section{Materials and Methods}

\subsection{Study Population}

A total of 510 adult patients (age $>18$ y) with CRS who underwent endoscopically guided bacterial culture from the sinus during ESS at the Asan Medical Center between January 2007 and December $2008(n=185)$, between January 2011 and December $2012(n=131)$, and between January 2017 and December $2018(n=194)$ were retrospectively enrolled in this study. All patients were diagnosed with CRS, according to the EPOS 2012 diagnostic criteria [1]. Each patient underwent an endoscopic exam and a computed tomography scan before ESS and was not treated with antibiotics or systemic or intranasal corticosteroids for at least four weeks before surgery. Demographic data (age, sex, current smoker), atopy status (positive result for specific IgE or skin prick test), and history of asthma were collected. According to EPOS criteria, 376 patients were diagnosed with CRSwNP, and 134 patients were diagnosed with CRSsNP. Patients who did not undergo bacterial culture during ESS or were diagnosed as fungal ball sinusitis, allergic fungal sinusitis, odontogenic sinusitis, immotile-cilia syndrome, or cystic fibrosis were excluded from this study. This study was approved by the Institutional Review Board of the Asan Medical Center, which exempted the study from requiring individual patient consent.

\subsection{Sample Collection}

Specimens were collected during ESS. The whole face, including the external nose and vestibule, was sterilized with chlorhexidine before ESS. ESS was performed by one of two experts (B.-J.L. or co-author J.H.K.). Purulent discharge in the maxillary and ethmoid sinuses was aseptically obtained using Blakesley forceps. If purulence was not observed on endoscopy, bacterial cultures were not performed during ESS. If purulence was observed on the side where surgery was performed first, bacterial culture was performed on that side. Collected specimens were placed into Thansystem (Copan Italia Spa, Brescia, Italy) collection units containing $5 \mathrm{~mL}$ of agar gel medium for aerobes and anaerobes and transferred to a microbiological laboratory for aerobic and anaerobic culture immediately following the procedure. Gram staining and quantitative cultures were performed. Each sample was inoculated onto plates of blood agar, MacConkey agar, and chocolate agar and then incubated at $37^{\circ} \mathrm{C}$ in a $5 \%$ $\mathrm{CO}_{2}$ incubator for aerobes. Samples inoculated onto Brucella agar were incubated in an anaerobic atmosphere using an anaerobic chamber. Plates were examined every day. All cultured bacteria were identified based on standard microbiologic techniques [8]. Both cultured bacteria and antibiotic resistance were recorded.

\subsection{Statistical Analyses}

All analyses were performed using a statistical software package (IBM SPSS Statistics for Windows, Version 22.0. Armonk, NY: IBM Corp). The chi-squared test statistic and student's $t$-test were used 
for group comparisons. A linear-by-linear association test was performed to identify increasing or decreasing trends of specific bacteria. Statistical significance was accepted for $p<0.05$.

\section{Results}

Bacteria were isolated from 389 of 510 patients (76.3\%). There were no differences between age or sex and positive culture ( $p=0.889$ and $p=0.835$, respectively) (Table 1 ). CRSsNP patients showed a significantly higher isolation rate than CRSwNP patients $(82.8 \%$ vs. $73.9 \%, p=0.038)$. However, there were no differences in isolation rates relative to atopy, asthma, or current smoker status $(p>0.05$ for each) (Table 2).

Table 1. Comparison of age and sex distribution according to the culture results.

\begin{tabular}{cccc}
\hline \multirow{2}{*}{ Variable } & \multicolumn{2}{c}{ Bacterial Culture } & $p$-Value \\
\cline { 2 - 3 } & $\begin{array}{c}\text { Positive } \\
(\boldsymbol{n}=\mathbf{3 8 9})\end{array}$ & $\begin{array}{c}\text { Negative } \\
(\boldsymbol{n}=\mathbf{1 2 1})\end{array}$ & \\
\hline Age (years), mean \pm S.D. & $47.2 \pm 17.0$ & $46.9 \pm 16.7$ & 0.889 \\
\hline Male gender, number (\%) & $237(60.9)$ & $75(62.0)$ & 0.835 \\
\hline
\end{tabular}

Table 2. Comparison of bacterial isolation rate according to the demographic data.

\begin{tabular}{ccccccccc}
\hline & \multicolumn{2}{c}{ Nasal Polyp } & \multicolumn{2}{c}{ Atopy } & \multicolumn{2}{c}{ Asthma } & \multicolumn{2}{c}{ Current Smoker } \\
\cline { 2 - 9 } & Yes & No & Yes & No & Yes & No & Yes & No \\
\hline No. of patients & 376 & 134 & 51 & 459 & 33 & 477 & 87 & 423 \\
Isolation rate, $\%$ & 73.9 & 82.8 & 66.7 & 77.3 & 72.7 & 76.5 & 75.9 & 76.4 \\
$p$-value & 0.038 & 0.089 & 0.625 & & 0.921 \\
\hline
\end{tabular}

A total of 650 strains were isolated from the 389 patients with positive cultures, and 193 patients $(49.6 \%)$ had a single isolated organism, while 196 patients $(50.4 \%)$ had multiple organisms. The most frequently isolated bacteria was coagulase-negative Staphylococcus (CNS) (28.0\%), followed by Streptococcus species (12.2\%), Propionibacterium species $(8.0 \%)$, Corynebacterium species $(7.5 \%)$, Staphylococcus aureus (6.2\%), Haemophilus species (5.7\%), Klebsiella species (5.1\%), Enterobacter species $(4.3 \%)$, and Pseudomonas aeruginosa (4.2\%) (Table 3). Streptococci, the second most common bacteria, were identified to the species level such as S. pneumoniae (4.6\%), S. constellatus $(3.4 \%)$, S. viridans $(1.8 \%)$, S. anginosus $(0.9 \%)$, S. intermedius $(0.8 \%)$, and others $(0.8 \%)$.

The isolation rates of specific bacteria between CRSsNP and CRSwNP patients were slightly different. S. pneumoniae, S. aureus, Corynebacterium, Peptostreptococcus species, Haemophilus species, Klebsiella species, and Citrobacter species were more frequent in CRSwNP patients, while S. constellatus, Parvimonas micra, and P. aeruginosa were more frequent in CRSsNP patients (Table 3).

Table 3. Number and percentage of bacterial isolates ( $n=650$ strains).

\begin{tabular}{cccr}
\hline \multicolumn{3}{c}{ Isolated Bacteria $[n(\%)]$} \\
\hline & $\begin{array}{c}\text { Total Isolates } \\
(\boldsymbol{n}=\mathbf{6 5 0})\end{array}$ & $\begin{array}{c}\text { CRSsNP } \\
(\boldsymbol{n}=\mathbf{1 9 6})\end{array}$ & $\begin{array}{c}\text { CRSwNP } \\
(\boldsymbol{n}=\mathbf{4 5 4})\end{array}$ \\
\hline Gram-positive aerobic and facultative anaerobic bacteria & & \\
Coagulase negative Staphylococcus & $182(28.0 \%)$ & $55(28.1 \%)$ & $127(28.0 \%)$ \\
Staphylococcus epidermidis & $159(24.5 \%)$ & $45(23.0 \%)$ & $114(25.1 \%)$ \\
Others & $23(3.5 \%)$ & $10(5.1 \%)$ & $13(2.9 \%)$ \\
\hline
\end{tabular}


Table 3. Cont.

\begin{tabular}{|c|c|c|c|}
\hline & \multicolumn{3}{|c|}{ Isolated Bacteria $[n(\%)]$} \\
\hline & $\begin{array}{l}\text { Total Isolates } \\
\quad(n=650)\end{array}$ & $\begin{array}{l}\text { CRSsNP } \\
(n=196)\end{array}$ & $\begin{array}{l}\text { CRSwNP } \\
(n=454)\end{array}$ \\
\hline Streptococcus species & $79(12.2 \%)$ & $32(16.3 \%)$ & $47(10.4 \%)$ \\
\hline Streptococcus pneumoniae & $30(4.6 \%)$ & $6(3.1 \%)$ & $24(5.3 \%)$ \\
\hline Streptococcus constellatus & $22(3.4 \%)$ & $14(7.1 \%)$ & $8(1.8 \%)$ \\
\hline Streptococcus viridans & $12(1.8 \%)$ & $5(2.6 \%)$ & $7(1.5 \%)$ \\
\hline Streptococcus anginosus & $6(0.9 \%)$ & $3(1.5 \%)$ & $3(0.6 \%)$ \\
\hline Streptococcus intermedius & $5(0.8 \%)$ & $4(2.0 \%)$ & $1(0.2 \%)$ \\
\hline Streptococcus group $C$ & $1(0.2 \%)$ & $0(0.0 \%)$ & $1(0.2 \%)$ \\
\hline Streptococcus group F & $1(0.2 \%)$ & $0(0.0 \%)$ & $1(0.2 \%)$ \\
\hline Streptococcus group $G$ & $1(0.2 \%)$ & $0(0.0 \%)$ & $1(0.2 \%)$ \\
\hline Streptococcus pseudopneumoniae & $1(0.2 \%)$ & $0(0.0 \%)$ & $1(0.2 \%)$ \\
\hline Corynebacterium & $49(7.5 \%)$ & $6(3.1 \%)$ & $43(9.5 \%)$ \\
\hline Staphylococcus aureus & $40(6.2 \%)$ & $10(5.1 \%)$ & $30(6.6 \%)$ \\
\hline Parvimonas micra & $21(3.2 \%)$ & $13(6.6 \%)$ & $8(1.8 \%)$ \\
\hline Peptostreptococcus species & $18(2.8 \%)$ & $2(1.0 \%)$ & $16(3.5 \%)$ \\
\hline \multicolumn{4}{|l|}{ Others } \\
\hline Peptoniphilus asaccharolyticus & $7(1.1 \%)$ & $2(1.0 \%)$ & $5(1.1 \%)$ \\
\hline Enterococcus & $4(0.6 \%)$ & $0(0.0 \%)$ & $4(0.9 \%)$ \\
\hline Bacillus & $2(0.3 \%)$ & $1(0.5 \%)$ & $1(0.2 \%)$ \\
\hline Micrococcus species & $1(0.2 \%)$ & $0(0.0 \%)$ & $1(0.2 \%)$ \\
\hline \multicolumn{4}{|c|}{ Gram-positive obligate anaerobic bacteria } \\
\hline Propionibacterium species & $52(8.0 \%)$ & $10(5.1 \%)$ & $42(9.3 \%)$ \\
\hline Clostridium species & $3(0.5 \%)$ & $1(0.5 \%)$ & $2(0.4 \%)$ \\
\hline \multicolumn{4}{|c|}{ Gram-negative aerobic and facultative anaerobic bacteria } \\
\hline Haemophilus species & $37(5.7 \%)$ & $6(3.1 \%)$ & $31(6.8 \%)$ \\
\hline Haemophilus influenzae & $33(5.1 \%)$ & $6(3.1 \%)$ & $27(5.9 \%)$ \\
\hline Others & $4(0.6 \%)$ & $0(0.0 \%)$ & $4(0.9 \%)$ \\
\hline Klebsiella species & $33(5.1 \%)$ & $7(3.6 \%)$ & $26(5.7 \%)$ \\
\hline Klebsiella aerogenes & $16(2.5 \%)$ & $3(1.5 \%)$ & $13(2.9 \%)$ \\
\hline Klebsiella pneumoniae & $13(2.0 \%)$ & $3(1.5 \%)$ & $10(2.2 \%)$ \\
\hline Klebsiella oxytoca & $4(0.6 \%)$ & $1(0.5 \%)$ & $3(0.7 \%)$ \\
\hline Enterobacter species & $28(4.3 \%)$ & $9(4.6 \%)$ & $19(4.2 \%)$ \\
\hline Citrobacter species & $6(0.9 \%)$ & $0(0.0 \%)$ & $6(1.3 \%)$ \\
\hline \multicolumn{4}{|l|}{ Others } \\
\hline Eggerthella lenta & $3(0.5 \%)$ & $3(1.5 \%)$ & $0(0.0 \%)$ \\
\hline Escherichia coli & $3(0.5 \%)$ & $1(0.5 \%)$ & $2(0.4 \%)$ \\
\hline Achromobacter xylosoxidans & $2(0.3 \%)$ & $1(0.5 \%)$ & $1(0.2 \%)$ \\
\hline Serratia & $2(0.3 \%)$ & $1(0.5 \%)$ & $1(0.2 \%)$ \\
\hline Morganella morganii & $2(0.3 \%)$ & $1(0.5 \%)$ & $1(0.2 \%)$ \\
\hline Campylobacter rectus & $1(0.2 \%)$ & $0(0.0 \%)$ & $1(0.2 \%)$ \\
\hline Eikenella corrodens & $1(0.2 \%)$ & $1(0.5 \%)$ & $0(0.0 \%)$ \\
\hline \multicolumn{4}{|c|}{ Gram-negative obligate aerobic bacteria } \\
\hline Pseudomonas aeruginosa & $27(4.2 \%)$ & $14(7.1 \%)$ & $13(2.9 \%)$ \\
\hline Moraxella & $5(0.8 \%)$ & $2(1.0 \%)$ & $3(0.7 \%)$ \\
\hline Acinetobacter & $1(0.2 \%)$ & $0(0.0 \%)$ & $1(0.2 \%)$ \\
\hline Neisseria subflava & $1(0.2 \%)$ & $0(0.0 \%)$ & $1(0.2 \%)$ \\
\hline Stenotrophomonas maltophilia & $1(0.2 \%)$ & $1(0.5 \%)$ & $0(0.0 \%)$ \\
\hline \multicolumn{4}{|c|}{ Gram-negative obligate anaerobic bacteria } \\
\hline Prevotella species & $17(2.6 \%)$ & $11(5.6 \%)$ & $6(1.3 \%)$ \\
\hline Fusobacterium species & $4(0.6 \%)$ & $4(2.0 \%)$ & $0(0.0 \%)$ \\
\hline Bacteroides & $2(0.3 \%)$ & $2(1.0 \%)$ & $0(0.0 \%)$ \\
\hline Porphyromonas species & $1(0.2 \%)$ & $0(0.0 \%)$ & $1(0.2 \%)$ \\
\hline
\end{tabular}

CRSsNP, chronic rhinosinusitis without nasal polyps; CRSwNP, chronic rhinosinusitis with nasal polyps. 
In order to identify the isolated bacteria differences between eosinophilic and non-eosinophilic CRSwNP, 58 patients with CRSwNP (with positive cultures between October 2017 and December 2018) were divided into non-eosinophilic CRSwNP and eosinophilic CRSwNP as defined by eosinophilic NPs when the proportion of eosinophils exceeded $10 \%$ of total inflammatory cells $[9,10]$. Forty-eight strains in 36 patients with eosinophilic CRSwNP and 38 strains in 22 patients with non-eosinophilic CRSwNP were isolated. S. epidermidis, Corynebacterium, and Enterobacter species were more frequent in eosinophilic CRSwNP patients (each $p<0.05$ ), and Haemophilus species, Klebsiella species, and $P$. aeruginosa were significantly more common in non-eosinophilic CRSwNP patients (each $p<0.05$ ) (Table 4).

Table 4. Comparison of the isolated bacteria in patients with non-eosinophilic and eosinophilic chronic rhinosinusitis with nasal polyps (CRSwNP) between October 2017 and December 2018.

\begin{tabular}{cccc}
\hline Organisms & $\begin{array}{c}\text { Eosinophilic CRSwNP } \\
(\boldsymbol{n}=\mathbf{4 8} \text { Strains) }(\mathbf{\%})\end{array}$ & $\begin{array}{c}\text { Non-eosinophilic CRSwNP } \\
(\boldsymbol{n}=\mathbf{3 8} \text { Strains) } \mathbf{( \% )}\end{array}$ & $\boldsymbol{p}$-Value \\
\hline Staphylococcus epidermidis & 46.0 & 26.0 & 0.003 \\
Streptococcus species & 8.0 & 16.0 & 0.082 \\
Corynebacterium species & 12.9 & 0.0 & $<0.001$ \\
Staphylococcus aureus & 8.0 & 5.0 & 0.390 \\
Haemophilus species & 0.0 & 10.9 & 0.001 \\
Klebsiella species & 21.0 & 37.0 & 0.013 \\
Enterobacter species & 4.0 & 0.0 & 0.043 \\
Pseudomonas aeruginosa & 0.0 & 5.0 & 0.024 \\
\hline
\end{tabular}

Next, trends of the above-listed bacteria between January 2007 and December 2018 were analyzed. First, the ten years were divided into three sections, 2007-2008, 2012-2013, and 2017-2018. Regarding the number of bacteria isolated in each period, 223 strains were identified between January 2007 and December 2008, 211 strains between January 2011 and December 2012, and 216 strains between January 2017 and December 2018. According to linear-by-linear association tests, CNS, Klebsiella species, and P. aeruginosa showed significant increasing trends ( $p=0.006, p=0.002$, and $p=0.007$, respectively), while Propionibacterium and Corynebacterium species showed significant decreasing trends $(p<0.001$ and $p=0.003$, respectively). However, no significant changes were found in Streptococcus, S. aureus, Haemophilus species, and Enterobacter species ( $p>0.05$ for each) (Table 5).

Table 5. Trends of frequently cultured bacteria over time.

\begin{tabular}{ccccc}
\hline Organisms & $\begin{array}{c}\mathbf{2 0 0 7 - 2 0 0 8} \\
(\boldsymbol{n}=\mathbf{2 2 3} \text { Strains }) \\
\mathbf{( \% )}\end{array}$ & $\begin{array}{c}\mathbf{2 0 1 2 - 2 0 1 3} \\
(\boldsymbol{n}=\mathbf{2 1 1} \text { Strains }) \\
\mathbf{( \% )}\end{array}$ & $\begin{array}{c}\mathbf{2 0 1 7 - 2 0 1 8} \\
(\boldsymbol{n = 2 1 6} \text { Strains }) \\
\mathbf{( \% )}\end{array}$ & $p$-Value \\
\hline CNS & 21.5 & 29.4 & 33.3 & 0.006 \\
Streptococcus species & 11.2 & 10.0 & 15.3 & 0.196 \\
Propionibacterium & 12.1 & 11.8 & 0.0 & $<0.001$ \\
species & 11.2 & 7.6 & 3.7 & 0.003 \\
Corynebacterium species & 8.1 & 4.3 & 6.0 & 0.364 \\
Staphylococcus aureus & 5.8 & 3.8 & 7.4 & 0.484 \\
Haemophilus species & 4.0 & 0.5 & 10.6 & 0.002 \\
Klebsiella species & 6.3 & 2.8 & 3.7 & 0.181 \\
Enterobacter species & 2.7 & 1.9 & 7.9 & 0.007 \\
Pseudomonas aeruginosa & & & & \\
\hline
\end{tabular}

When trends of antibiotic resistance among frequently cultured bacteria were analyzed with linear-by-linear association tests, extended-spectrum beta-lactamase (ESBL)-producing Klebsiella and Enterobacter species were significantly increased, most notably in the most recent 2017-2018 $(p<0.001$ and $p=0.007$, respectively) (Table 6). The same results were obtained when analyzing the ratio 
of resistant bacteria per each bacterium in each period (data not shown, $p=0.004$ and $p<0.001$, respectively). However, methicillin-resistant $S$. aureus (MRSA) and ciprofloxacin-resistant $p$. aeruginosa were not increased.

Table 6. Trends in the antibiotic resistance of frequently cultured bacteria over time.

\begin{tabular}{|c|c|c|c|c|}
\hline $\begin{array}{c}\text { Organism } \\
\text { Antibiotic Resistance }\end{array}$ & $\begin{array}{c}2007-2008 \\
(n=223 \text { Strains }) \\
n(\%)\end{array}$ & $\begin{array}{c}2012-2013 \\
(n=211 \text { Strains }) \\
n(\%)\end{array}$ & $\begin{array}{c}2017-2018 \\
(n=216 \text { Strains }) \\
n(\%)\end{array}$ & $p$-Value \\
\hline \multicolumn{5}{|l|}{ Streptococcus species } \\
\hline Amoxicillin/clavulanate & $0(0.0 \%)$ & $0(0.0 \%)$ & $2(0.9 \%)$ & 0.082 \\
\hline Macrolide $^{\mathrm{a}}$ & $8(3.6 \%)$ & $10(4.7 \%)$ & $13(6.0 \%)$ & 0.233 \\
\hline \multicolumn{5}{|l|}{ Staphylococcus aureus } \\
\hline $\begin{array}{l}\text { Methicillin } \\
\text { Haemophilus species }\end{array}$ & $2(0.9 \%)$ & $1(0.5 \%)$ & $2(0.9 \%)$ & 0.977 \\
\hline $\begin{array}{l}\text { Ampicillin } \\
\text { Klebsiella species }\end{array}$ & $8(34.8 \%)$ & $1(0.5 \%)$ & $10(4.6 \%)$ & 0.532 \\
\hline ESBL & $1(0.4 \%)$ & $1(0.5 \%)$ & $16(7.4 \%)$ & $<0.001$ \\
\hline Ciprofloxacin & $1(0.4 \%)$ & $0(0.0 \%)$ & $0(0.0 \%)$ & 0.229 \\
\hline \multicolumn{5}{|l|}{ Enterobacter species } \\
\hline ESBL & $0(0.0 \%)$ & $6(2.8 \%)$ & $8(3.7 \%)$ & 0.007 \\
\hline Ciprofloxacin & $0(0.0 \%)$ & $0(0.0 \%)$ & $0(0.0 \%)$ & $\mathrm{N} / \mathrm{A}$ \\
\hline \multicolumn{5}{|l|}{ Pseudomonas aeruginosa } \\
\hline ESBL & $0(0.0 \%)$ & $0(0.0 \%)$ & $0(0.0 \%)$ & $\mathrm{N} / \mathrm{A}$ \\
\hline Ciprofloxacin & $0(0.0 \%)$ & $0(0.0 \%)$ & $2(0.9 \%)$ & 0.082 \\
\hline
\end{tabular}

N/A, not available; ESBL, extended-spectrum beta-lactamase; ${ }^{a}$ Macrolide includes azithromycin, erythromycin, and clarithromycin.

\section{Discussion}

The overuse or misuse of broad-spectrum antibiotics may cause alterations in organisms that lead to the persistence or recurrence of sinusitis [11]. Therefore, elucidating recent trends in bacterial cultures from CRS patients is important for infection management and prevention of antibiotic resistance.

In this study on the bacteriology of Korean adult CRS patients over the past 10 years, we found that gram-positive aerobic and facultative anaerobic bacteria were the major isolates, primarily CNS (28.0\%) and Streptococcus species (12.2\%). Furthermore, gram-negative bacteria represented $29.1 \%$ of the bacterial species isolated. Among gram-negative species, the most common were H. influenzae $(5.7 \%)$, Klebsiella species (5.1\%), Enterobacter $(4.3 \%)$, and P. aeruginosa $(4.2 \%)$. Obligate anaerobes represented $12.9 \%$, which was primarily comprised of Propionibacterium $(8.0 \%)$ and Prevotella $(3.2 \%)$. These results are similar but different from previous studies. A systematic review of endoscopically derived bacterial cultures in CRS published between 1975 and 2010 showed that the composition of species was predominantly CNS (24.8\%) and S. aureus (18.9\%), followed by H. influenzae $(9.6 \%)$, P. aeruginosa (7.8\%), S. pneumonia (7.0\%), Peptostreptococcus species (6.1\%), and Bacteroides (6.0\%) [2]. A study that enrolled 32 CRS patients in the United States between 1987 and 2004 reported that the most common aerobic and facultative bacteria were $\alpha$-hemolytic streptococci $(21.9 \%)$, Enterobacteriaceae (Escherichia coli, Proteus mirabilis, K. pneumoniae) (21.9\%), and S aureus (15.6\%), and the predominant anaerobic bacteria were Peptostreptococcus species (50.0\%), Prevotella species (43.8\%), and Fusobacterium species (25.0\%) [12]. Bacterial culture results of biopsy specimens from anterior ethmoidal mucosa of 43 CRS patients in Germany showed that CNS (81.4\%), Corynebacterium species (41.9\%), $\alpha$-hemolytic streptococci $(20.9 \%)$, and S. aureus $(18.6 \%)$ were the major aerobic organisms, and Propionibacterium (76.7\%) and Peptostreptococcus species (25.6\%) were the most common anaerobes [13].

In our study, the isolation rate of $S$. aureus $(6.2 \%)$ in Korean adult CRS patients was low compared to previous studies. However, the systematic review included various compounding factors, such as the location of the specimen collection (outpatient clinic and operating room), site of culture (middle meatus and sinus), and technique (swab, aspirate, and mucosal biopsy) [2]. Another recent study 
involving 202 Chinese CRS patients between 2014 and 2016 reported that the most common bacteria isolated from middle meatus swab samples were CNS, Corynebacterium, and S. aureus [6]. They also collected specimens from the middle meatus before or during surgery. On the other hand, we collected specimens from the sinus in the operating room. Another reason for the discrepancy may be due to different environmental and medical factors. Other previous studies collected endoscopically guided samples from non-Asian CRS patients [12,13]. In South Korea, the isolation rate of S. aureus in the sinus has been reported to be less than $10 \%$. A study in 81 CRSwNP patients who underwent ESS between 2002 and 2004 in South Korea reported that the isolation rate of S. aureus in the maxillary sinus of 61 adult patients was $7.8 \%$ ( 5 of 64 isolates), which was different from the $19.1 \%$ (13 of 68 isolates) isolation rate for middle meatus specimens [7]. Our center previously reported that the isolation rate of S. aureus was also $5.5 \%$ in bacterial cultures obtained from a maxillary sinus during ESS for 71 patients with CRSwNP that was diagnosed between 2007 and 2012 [8].

Other than these studies, reports of bacteriology of CRS in large patient populations are lacking in South Korea. Our study involved CRSsNP as well as CRSwNP patients and included recent data. The isolation rates for bacteria were significantly higher in CRSsNP patients than in CRSwNP patients. This result is slightly different from the results of previous studies, which reported no significant differences in isolation rates between CRSsNP and CRSwNP patients $[6,13,14]$. Nevertheless, the bacterial isolation rate of CRSwNP (73.9\%) was notably high, as in previous studies. S. pneumoniae, S. aureus, Corynebacterium, Peptostreptococcus species, Haemophilus species, Klebsiella species, and Citrobacter species appear to be more common in CRSwNP patients compared to CRSsNP patients like in earlier Chinese studies [6,14]. Especially, S. epidermidis, Corynebacterium species, and Enterobacter species were significantly associated with eosinophilic CRSwNP and Haemophilus species, Klebsiella species, and P. aeruginosa with non-eosinophilic CRSwNP. Non-eosinophilic CRSwNP has been expected to be more affected by a bacterial infection and different microbiology compared to eosinophilic CRSwNP since non-eosinophilic CRSwNP is associated with Th1 and Th17 immune response but eosinophilic CRSwNP with Th2 response $[15,16]$. However, our results suggest that eosinophilic CRSwNP could be affected by bacteria as well as non-eosinophilic CRSwNP. Although slightly different from our results, a study in Japan, including 51 isolates of 29 patients, also demonstrated isolation rate of bacteria were high $(90 \%)$ in eosinophilic CRSwNP patients, which were not different with neutrophilic CRSwNP $(98 \%)$ and no differences in detected bacteria between two groups [16]. Two other previous studies showed that $S$. aureus were increased in CRSwNP with blood eosinophilia, [6] and significantly less gram-negative aerobic and facultative anaerobic bacteria were isolated from the CRS patients with blood eosinophilia [14]. Therefore, bacteria may play a role in the pathophysiology of CRSwNP and CRSsNP, regardless of eosinophilic inflammation.

We found a high prevalence of CNS in both CRSsNP and CRSwNP patients with S. epidermidis presenting the majority of isolated CNS. The role of CNS in the pathogenesis of CRS remains controversial as it can be frequently found in the middle meatus of healthy individuals as well as CRS patients $[6,14,17]$. Scant or light growth likely represents contamination, whereas moderate to heavy growth, with many WBCs on a gram stain, may be an actual infection [4]. It has been proven (using in vitro biofilm assay and a rat central venous catheter infection model) that certain strains of CNS can form biofilm [18]. Zhang et al. found that $28 \%$ of CRS patients had CNS as their only isolate, and were significantly more likely to have preoperative antibiotics but less likely to have preoperative systemic steroids and a prior ESS compared to patients with all other positive culture results. However, the Lund-Mackay CT and symptoms scores were not associated with the single result of CNS in a multiple logistic regression model [19].

A concern about increases in atypical bacteria and antibiotic-resistant organisms motivated us to investigate trends in the species composition of isolated bacteria and antibiotic resistance. When these trends over the last ten years were analyzed, CNS, Klebsiella species, and P. aeruginosa showed increasing trends that were significant. Since Klebsiella species and P. aeruginosa were not prevalent in past studies, their increase may raise awareness of the increase in gram-negative bacteria and their role 
in CRS; hence, antimicrobial therapy based on the culture results should be considered [20]. Moreover, we found that ESBL-producing Klebsiella and Enterobacter species have tended to increase significantly in recent years. Antibiotics have been recommended to treat these pathogens associated with acute or chronic infection [21]. The emergence of gram-negative bacteria or MRSA by empirical and repeated use of antibiotics can cause more recalcitrant CRS [22]. Acquiring an endoscopically guided culture can alleviate such problems and can lead to more successful treatments. This recommendation agrees with another study that also emphasized the importance of culture-directed antibiotic treatment to prevent antimicrobial resistance [23].

\section{Conclusions}

In bacterial cultures obtained from the sinus during ESS, even though gram-positive bacteria were the most frequently isolated strains in patients with CRS, gram-negative bacteria such as Klebsiella species and P. aeruginosa showed a significantly increasing trend. Furthermore, ESBL-producing Klebsiella and Enterobacter species appeared with an increasing trend in recent years. These findings support the current recommendation of using antibiotics targeted to positive cultures of infectious exacerbations in CRS patients, ideally with endoscopically guided cultures. We should be careful about using empirical antibiotics in patients with CRS. In addition, endoscopically guided cultures from the sinus during ESS may be helpful for the management of CRS patients by identifying pathogenic bacteria and their antimicrobial susceptibilities.

Author Contributions: J.H.K. participated in the conceptualization, study design, supervision, data analysis, data interpretation, and writing of the article. D.K. and A.M.A. participated in the acquisition and interpretation of data and writing of the article. D.K., A.M.A., and J.H.K. have approved the submitted version.

Funding: This study was supported by grants (2018-769 and 2019-769) from the Asan Institute for Life Sciences, Asan Medical Center, Seoul, Korea, and by the Basic Science Research Program through the National Research Foundation of Korea (NRF), funded by the Ministry of Science, ICT \& Future Planning (2017R1D1A1B03031452).

Acknowledgments: We would like to thank Bong-Jae Lee, who retired in Feb 2018, for collecting data.

Conflicts of Interest: The authors declare no conflict of interest.

\section{References}

1. Fokkens, W.J.; Lund, V.J.; Mullol, J.; Bachert, C.; Alobid, I.; Baroody, F.; Cohen, N.; Cervin, A.; Douglas, R.; Gevaert, P.; et al. European Position Paper on Rhinosinusitis and Nasal Polyps 2012. Rhinol. Suppl. 2012, 23, $1-298$.

2. Thanasumpun, T.; Batra, P.S. Endoscopically-derived bacterial cultures in chronic rhinosinusitis: A systematic review. Am. J. Otolaryngol. 2015, 36, 686-691. [CrossRef] [PubMed]

3. Sivasubramaniam, R.; Douglas, R. The microbiome and chronic rhinosinusitis. World J. Otorhinolaryngol. Head Neck Surg. 2018, 4, 216-221. [CrossRef] [PubMed]

4. Manes, R.P.; Batra, P.S. Bacteriology and antibiotic resistance in chronic rhinosinusitis. Facial Plast. Surg. Clin. N. Am. 2012, 20, 87-91. [CrossRef]

5. Jiang, R.S.; Su, M.C.; Liao, C.Y.; Lin, J.F. Bacteriology of chronic sinusitis in relation to middle meatal secretion. Am. J. Rhinol. 2006, 20, 173-176. [CrossRef]

6. Wei, H.Z.; Li, Y.C.; Wang, X.D.; Lu, X.X.; Hu, C.H.; He, S.; Liu, X. The microbiology of chronic rhinosinusitis with and without nasal polyps. Eur. Arch. Otorhinolaryngol. 2018, 275, 1439-1447. [CrossRef]

7. Kim, H.J.; Lee, K.; Yoo, J.B.; Song, J.W.; Yoon, J.H. Bacteriological findings and antimicrobial susceptibility in chronic sinusitis with nasal polyp. Acta Otolaryngol. 2006, 126, 489-497.

8. Lee, C.W.; Lee, B.J.; Yoo, S.H.; Yi, J.S. Relationship between positive bacterial culture in maxillary sinus and surgical outcomes in chronic rhinosinusitis with nasal polyps. Auris Nasus Larynx 2014, 41, 446-449. [CrossRef]

9. Cao, P.P.; Li, H.B.; Wang, B.F.; Wang, S.B.; You, X.J.; Cui, Y.H.; Wang, D.Y.; Desrosiers, M.; Liu, Z. Distinct immunopathologic characteristics of various types of chronic rhinosinusitis in adult Chinese. J. Allergy Clin. Immunol. 2009, 124, 478-484. [CrossRef] 
10. Lee, M.; Kim, D.W.; Yoon, H.; So, D.; Khalmuratova, R.; Rhee, C.S.; Park, J.W.; Shin, H.W. Sirtuin 1 attenuates nasal polypogenesis by suppressing epithelial-to-mesenchymal transition. J. Allergy Clin. Immunol. 2016, 137, 87-98. [CrossRef]

11. Yildirim, A.; Oh, C.; Erdem, H.; Kunt, T. Bacteriology in patients with chronic sinusitis who have been medically and surgically treated. Ear Nose Throat J. 2004, 83, 836-838. [CrossRef] [PubMed]

12. Brook, I. Bacteriology of chronic sinusitis and acute exacerbation of chronic sinusitis. Arch. Otolaryngol. Head Neck Surg. 2006, 132, 1099-1101. [CrossRef] [PubMed]

13. Niederfuhr, A.; Kirsche, H.; Riechelmann, H.; Wellinghausen, N. The bacteriology of chronic rhinosinusitis with and without nasal polyps. Arch. Otolaryngol. Head Neck Surg. 2009, 135, 131-136. [CrossRef] [PubMed]

14. Liu, Q.; Lu, X.; Bo, M.; Qing, H.; Wang, X.; Zhang, L. The microbiology of chronic rhinosinusitis with and without nasal polyps. Acta Otolaryngol. 2014, 134, 1251-1258. [CrossRef] [PubMed]

15. Tomassen, P.; Vandeplas, G.; Van Zele, T.; Cardell, L.O.; Arebro, J.; Olze, H.; Förster-Ruhrmann, U.; Kowalski, M.L.; Olszewska-Ziąber, A.; Holtappels, G.; et al. Inflammatory endotypes of chronic rhinosinusitis based on cluster analysis of biomarkers. J. Allergy Clin. Immunol. 2016, 137, 1449-1456. [CrossRef] [PubMed]

16. Hirotsu, M.; Kikuchi, K.; Kusunoki, T.; Kase, K.; Ono, N.; Ikeda, K. Comparison of bacterial examinations between eosinophilic and neutrophilic chronic rhinosinusitis with nasal polyps. Acta Otolaryngol. 2011, 131, 997-1001. [CrossRef] [PubMed]

17. Araujo, E.; Dall, C.; Cantarelli, V.; Pereira, A.; Mariante, A.R. Microbiology of middle meatus in chronic rhinosinusitis. Braz. J. Otorhinolaryngol. 2007, 73, 549-555. [CrossRef]

18. Li, H.; Xu, L.; Wang, J.; Wen, Y.; Vuong, C.; Otto, M.; Gao, Q. Conversion of Staphylococcus epidermidis strains from commensal to invasive by expression of the ica locus encoding production of biofilm exopolysaccharide. Infect. Immun. 2005, 73, 3188-3191. [CrossRef]

19. Zhang, Z.; Adappa, N.D.; Lautenbach, E.; Chiu, A.G.; Doghramji, L.J.; Cohen, N.A.; Palmer, J.N. Coagulase-negative Staphylococcus culture in chronic rhinosinusitis. Int. Forum Allergy Rhinol. 2015, 5, 204-213. [CrossRef]

20. Cincik, H.; Ferguson, B.J. The impact of endoscopic cultures on care in rhinosinusitis. Laryngoscope 2006, 116, 1562-1568. [CrossRef]

21. Hamilos, D.L. Chronic rhinosinusitis: Epidemiology and medical management. J. Allergy Clin. Immunol. 2011, 128, 693-707. [CrossRef] [PubMed]

22. Tichenor, W.S.; Adinoff, A.; Smart, B.; Hamilos, D.L. Nasal and sinus endoscopy for medical management of resistant rhinosinusitis, including postsurgical patients. J. Allergy Clin. Immunol. 2008, 121, 917-927. [CrossRef] [PubMed]

23. Bhattacharyya, N.; Kepnes, L.J. The risk of development of antimicrobial resistance in individual patients with chronic rhinosinusitis. Arch. Otolaryngol. Head Neck Surg. 2004, 130, 1201-1204. [CrossRef] [PubMed] 